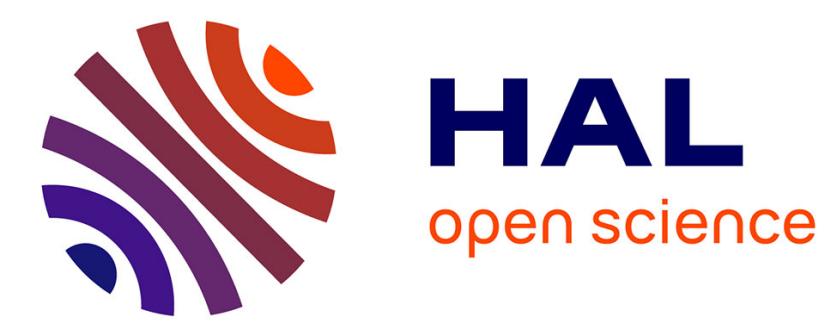

\title{
Multi-objective optimisation of the management of electric bus fleet charging
}

Adnane Houbbadi, Rochdi Trigui, Serge Pelissier, Eduardo Redondo-Iglesias, Tanguy Bouton

\section{- To cite this version:}

Adnane Houbbadi, Rochdi Trigui, Serge Pelissier, Eduardo Redondo-Iglesias, Tanguy Bouton. Multiobjective optimisation of the management of electric bus fleet charging. VPPC2017, Dec 2017, BELFORT, France. hal-01739878

\section{HAL Id: hal-01739878 https://hal.science/hal-01739878}

Submitted on 21 Mar 2018

HAL is a multi-disciplinary open access archive for the deposit and dissemination of scientific research documents, whether they are published or not. The documents may come from teaching and research institutions in France or abroad, or from public or private research centers.
L'archive ouverte pluridisciplinaire HAL, est destinée au dépôt et à la diffusion de documents scientifiques de niveau recherche, publiés ou non, émanant des établissements d'enseignement et de recherche français ou étrangers, des laboratoires publics ou privés. 


\section{Multi-objective optimisation of the management of electric bus fleet charging}

\author{
Adnane Houbbadi, Rochdi Trigui, Serge Pelissier, \\ Eduardo Redondo-Iglesias \\ Univ Lyon, IFSTTAR, AME, LTE \\ F-69675, LYON, France \\ Adnane.houbbadi@ifsttar.fr
}

\author{
Tanguy Bouton \\ TRANSDEV \\ Paris, France \\ Tanguy.BOUTON@transdev.com
}

\begin{abstract}
The paper introduces a methodical approach which can be used to identify the optimum charging strategy for a fleet of electrical-powered buses. The methodical approach allows minimizing the energy consumption, the peak load demand and ageing of the batteries. This method uses optimisation algorithms to search for optimal plans taking into account technical constraints.
\end{abstract}

Keywords- Electric bus fleet, Optimisation, Evolutionary algorithms, Genetic algorithms, Battery ageing

\section{LIST OF ABREVIATIONS}

EV Electric Vehicle

EB Electric Bus

EA Evolutionary Algorithms

SOC State Of Charge

NSGA Non-Dominated Sorting Genetic Algorithm

\section{INTRODUCTION}

The transport sector in Europe is the fastest growing consumer of energy and producer of greenhouse gases GHG. The emissions from road transport are the main source of GHG emissions [1]. In Europe, EU has committed to cut its emissions of greenhouse gases GHG to 20\% below 1990 levels by 2020 , $40 \%$ by 2030 and $80 \%$ for 2050 by using plug-in hybrid and electric cars that will allow for steeper emissions reductions [2].

Therefore, electrification of the road transport is a key aspect to achieve these objectives and a way to reduce the EU's dependency on fossil energy sources. However, the large-scale deployment of EVs is not an easy task. This transition will have a great impact on the electric system, generating network congestion problems and requiring more electricity generation to cover the peak demand [3].

In order to optimise the charging schedules and reduce the peak demand, an optimisation methodology for energy management for electric bus fleet has been developed. The capability of controlling the driving cycle, scheduling the recharge operations and communicating with the grid, EVs and charging stations, allows then adopting smart strategies in order to reduce energy consumption, peak load demand and battery ageing with regard to technical constraints.

This paper is organised as follows. In the first section, we introduce and discuss our proposed approach for smart charging of electric vehicles. In the next section, we show the simulation setup used for a case study applied to existing bus line. Then, we present and discuss our results. In the last section, we draw some conclusions and present some future work.

\section{PROPOSED APPROACH}

\section{A. Methodology}

An optimisation methodology for energy management for electric bus fleet is proposed in (Fig. 1) in Matlab/Simulink environment. The main idea of the approach is that an electric bus model and a battery model were first developed based on an electric model on VEHLIB software [4]. VEHLIB is a systemic vehicle simulation software, developed by IFSTTAR-LTE to cope with the energetic and dynamic performances evaluation of conventional, electric and hybrid vehicles.

Thus, we proposed different optimisation algorithms and methods already tested in the literature [5] that are the most suitable for solving nonlinear problems.

The optimisation methodology consists of the interaction of several sub-models, which are managed by an optimisation tool. The optimisation tool exchanges data with sub-models receiving back the state of charge, temperature and the ageing of the battery and assigning the optimal charging schedules.

In this case, the optimisation tool for the management of electric bus fleet charging is divided on two parts. The first part is about the battery discharging process during the bus operation. The second part is about the battery charging process once the bus arrived in the bus depot.

The different sub-models that occur during the discharge of the battery are presented in (Fig. 1) below:

Bus line descriptions: Bus lines characteristics are defined by: number of stops, distance, altitude, weight data ...

Electric Bus model: Calculate the vehicle energy consumption, the studied electric bus is modelled and simulated using the Matlab-Simulink based VEHLIB software. 


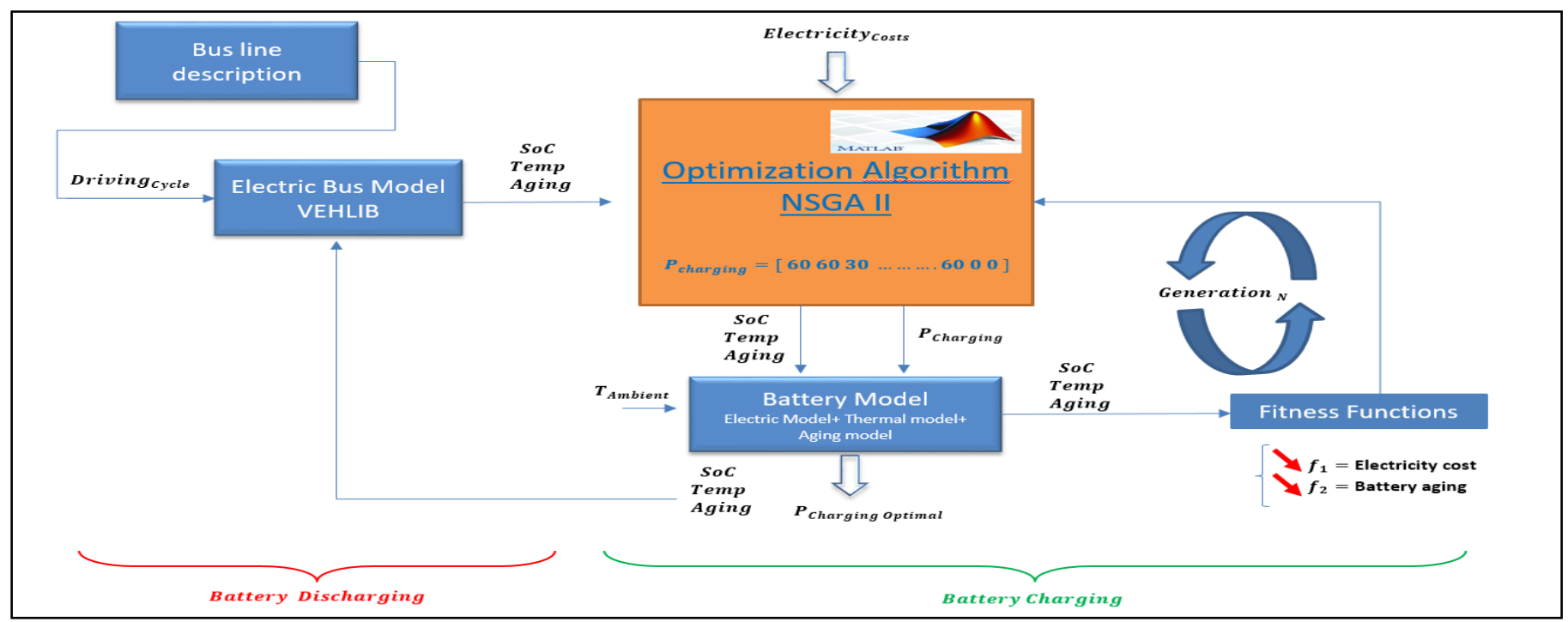

Fig. 1. Optimisation tool for the management of electric bus fleet charging

As the other simulation tools, the software requires the definition of a vehicle architecture through the choice of an appropriate combination of components models in a library (internal combustion engine, electrical machines, battery, transmission, control unit, etc.). Then a specific speed profile is defined, such as standard driving cycles for buses (SORT), or a real driving schedule (RATP AQA21).

The different sub-models that occur during the charge of the battery are presented below:

Optimisation algorithm: represent the main model for the optimisation tool. $\mathrm{Hu}$ and Morais [5] compared several algorithms for smart charging of electric vehicles through an extensive literature review. Existing works on the optimisation of the charging of electric vehicle fleets have suggested different solutions. Galván-López and Curran [6] used a stochastic optimisation evolutionary algorithm for a multi-objective problem, Alonso and Amaris [7] used heuristic smart charging algorithms. The choice of the optimisation algorithm strongly depends on the objective functions, the required quality of solutions, the computing time, the problem's constraints, etc... Some deterministic algorithms can be very fast but in many cases they can only be applied for small size problems, they are more efficient where only a single objective function is required and the number of constraints is reduced. In this paper, regarding to the complex, large-scale (EBs fleet) optimisation problems with high number of constraints, Evolutionary algorithms (EA) have been selected for dealing with non-linear and non-convex problems and because they offer great flexibility to consider multi-objective functions and ability to work with several constraints.

Battery model: The Battery model illustrated in (Fig. 2) contains a previously developed electric model based on VEHLIB, a simple thermal model of a large prismatic Li-ion battery (LiFePO4/graphite) based on an equivalent electrical circuit [8] and an Eyring acceleration model for predicting calendar ageing of lithium-ion batteries [9].

In order to simplify the thermal model, we supposed that the temperature at the core and terminals of a battery cell is the same and cell temperatures in the battery pack are homogeneous. The studied one node thermal model contains one heat capacity that represents heat accumulation and a thermal resistance that represents heat transfers with ambient air. There is no cooling system. The parameter values of the thermal model were determined from [8].

The ageing model takes into account the calendar ageing of lithium-ion LFP/C cells, which seems to be predominant in batteries used in applications such as electric vehicle. The cycling ageing could also be important in some cases but not during the charging time particularly in this case, when the battery is charged with a C-rate of $\mathrm{C} / 6$.

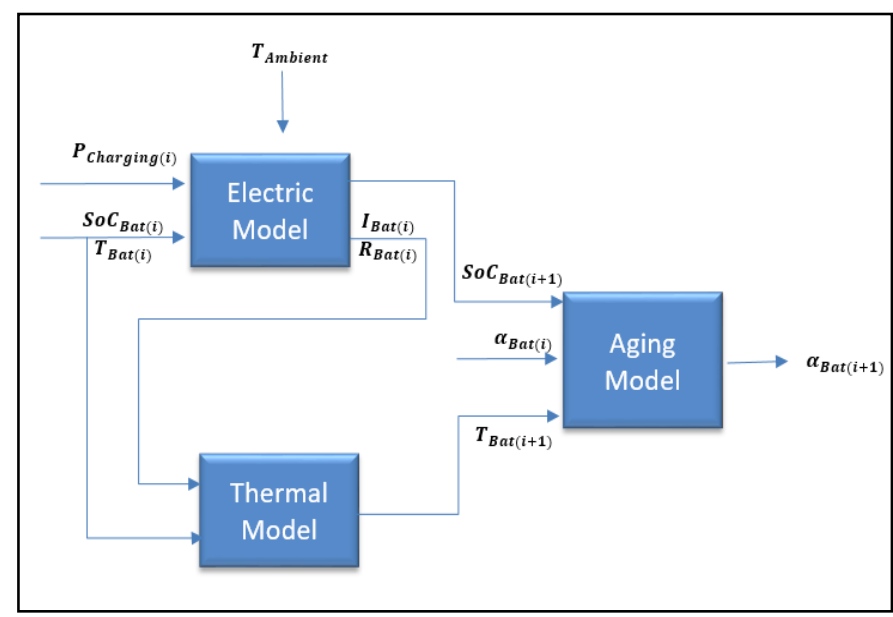

Fig. 2. Battery model of the studied electric bus

In a first approach, the calendar ageing is represented by Eq. (1):

$$
Q_{l}=A \cdot e^{\left(\frac{-E_{a}}{k \cdot T}+B \cdot Q_{a}\right)} t
$$

with $Q_{l}$ the capacity fade (p.u.), A the pre-exponential factor (p.u./day), Ea the activation energy for the reaction $(\mathrm{eV}), \mathrm{k}$ the Boltzmann constant $(\mathrm{eV} / \mathrm{K})$, T the absolute temperature $(\mathrm{K}), \mathrm{B}$ the quantity of charge factor (no units), Qa available quantity of charge (p.u.), t time (day). The charging period is divided into 30 minutes time slot and we supposed that $Q_{a}$ and $T$ are constant during this slot. The calendar ageing could be modelled by the 
variation of capacity fade as function of time obtained by deriving Eq. (1).

$$
\frac{d Q_{l}}{d t}=A \cdot e^{\left(\frac{-E a}{k \cdot T}+B \cdot Q_{a}\right)}
$$

All the constants will be determined from literature [9].

\section{B. Multi-objective optimisation problem description}

\section{Multi-objective Evolutionary algorithm}

Evolutionary algorithm (EA) is a subset of evolutionary computation, a generic population-based metaheuristic optimisation algorithm. An EA uses mechanisms inspired by biological evolution, such as reproduction, mutation, recombination, and selection. Candidate solutions to the optimisation problem play the role of individuals in a population, and the fitness function determines the quality of the solutions [10]. A significant portion of research and application in the field of optimisation considers a single objective, although most real problems involve more than one objective. With the presence of multiple conflicting objective (such as simultaneously minimizing the electricity cost and maximizing the battery lifetime), EA resorts to a number of trade-off optimal solutions (Pareto Front). Besides, EAs do not require any specific knowledge of the fitness function. They work even when it is not possible to define a gradient on the fitness function.

Genetic algorithm (GA) is the most popular type of EA. GA seeks the solution of a problem in the form of strings of numbers, by applying operators such as recombination and mutation (sometimes one, sometimes both). This type of EA is often used in optimisation problems.

\section{Non-dominated Sorting Approach}

Non-Dominated Sorting Genetic Algorithm (NSGA-II) is a genetic algorithm given to solve the Multi-Objective Optimisation problems. It was proposed by Deb et.al in 2002 [11]. The NSGA varies from simple genetic algorithm only in the way the selection operator works. The idea behind the NSGA-II is that before the selection is performed, the population is sorted according to two attributes: the non-domination rank and the crowding distance. That is, between two individuals with differing non-domination ranks, we prefer the solution with the lower (better) rank. Otherwise, if both solutions belong to the same front, then we prefer the solution that is located in a lesser crowded region.

Initially, a random parent population $P_{0}$ size $\mathrm{N}$ is created at generation $G E N=0$. At each generation $(\mathrm{g})$, every individual within the population $P_{g}$ is evaluated and sorted based on the non-domination sort (rank + crowding distance) corresponding to their position in the front they belong. Then, a selection mechanism by tournament takes place to stochastically pick the fittest individuals from the population. The selected individuals are modified by genetic operators (crossover, mutation) and are used to create an offspring population $Q_{g}$ of size $\mathrm{N}$. The current population composed of parent and offspring population $P_{g}+$ $Q_{g}$ is in turn evaluated and sorted based on non-domination sort, then is replaced by current population individuals based on rank and crowding distance until the population size $\mathrm{N}$ is reached. This new population of size $\mathrm{N}$ represents the new population $P_{g+1}$ at generation $G E N+1$. The process stops until the number of generation is satisfied. The flow chart is presented in (Fig. 3).

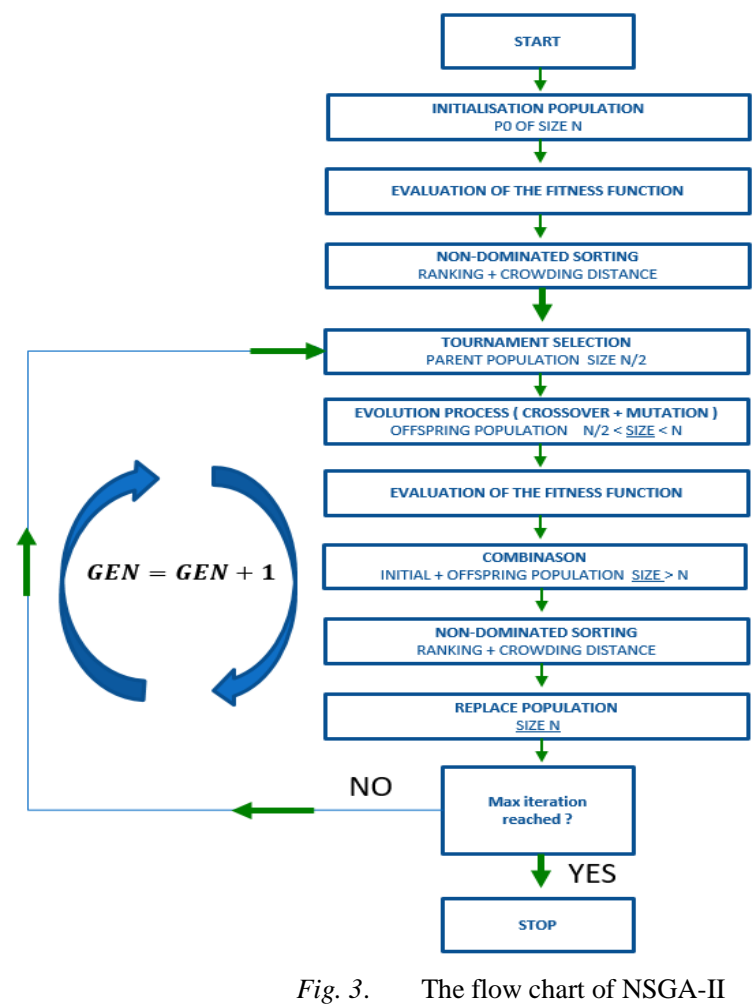

\section{Design optimisation variables}

In this work, we use a variable charging power $P_{1}$ in a row vector, where each column indicates the charging power of the EB during a particular time period (30 min).

In our work, the time-slots are of length $30 \mathrm{~min}$, starting at $T_{i}$ and running to $T_{f}$. Therefore, the charging power schedule can be represented by a matrix:

$$
P_{1}=\left[P_{1}^{T_{i}}, P_{1}^{T_{i}+30}, \ldots, P_{1}^{T_{f}}\right]
$$

In $E q$. (3), the index 1 refers to one electric bus, the index $T$ refers to a time-slot of $30 \mathrm{~min}$. The individual $P_{1}$ represents the charging behavior of a single EB over the full period and each column represents the charging behavior at a single time-slot.

\section{Objective functions}

We are interested in this work in looking for optimal charging schedules in order to reduce the charging costs and battery ageing.

Thus, we aim to minimise $f_{\text {cost }}$

$$
f_{\text {cost }}=\sum_{i=T_{i}}^{T_{f}} P_{1}^{i} \times t \times E_{\text {costs }}^{i}
$$

Where $P_{1}{ }^{i}$ represents the charging power of a single EB $(\mathrm{kW}), t$ represents the time-slot (h), and $E_{\text {costs }}{ }^{i}$ the electricity costs of a given scheduling $(€ / \mathrm{kWh})$. 
We consider the second objective, which is the battery ageing. As indicated previously, during the charging phase, the battery is charged with a low current so we use a fitness function from Eq. (2) that calculates the variation of capacity fade in case of calendar ageing. We aim to minimise $f_{\text {aging }}$

$$
\begin{aligned}
& V^{i}=A \cdot e^{\left(\frac{-E_{a}}{k \cdot T^{i}}+B \cdot Q_{a}{ }^{i}\right)} \\
& f_{\text {aging }}=\sum_{i=T_{i}}^{T_{f}} V^{i} \times t
\end{aligned}
$$

Where $V^{i}$ represents the capacity fade (p.u./min) of a given scheduling and $\mathrm{t}$ represents the time-slot ( $\mathrm{min})$.

\section{Constraints and Variable Bounds}

Here we considered a constant charging power ranged from 0 to $60 \mathrm{~kW}$. The charging power variables $P_{1}$ could take the value of 0 or 30 or $60 \mathrm{~kW}$ during a time period of 30 minutes.

$P_{1}{ }^{i}=\left\{\begin{array}{l}0 \\ 30 \\ 60\end{array} \quad 0 \leq P_{1}{ }^{i} \leq 60 \quad i=T_{i}\right.$ to $T_{f}$

At the end of the charging time, we have to get the battery fully charged which means that the capacity passed during charge to the battery plus the capacity present initially in the battery must be equal to the total battery capacity.

Eq. (8) summarises the constraint equation:

$$
\sum_{i=T_{i}}^{T_{f}} \frac{P_{1}{ }^{i} \times t \times \eta}{V}=\frac{\left(S_{0} C_{100 \%}-S o C_{\text {initial }}\right) \times \text { Bat }_{\text {Capacity }}}{100}
$$

Where $P_{1}{ }^{i}$ represents the charging power of a single EB (W), $t$ the time-slot (h), $\eta$ the battery and inverter efficiency $(\%), V$ the nominal battery voltage (Volt) and Bat Capacity $_{\text {represents the }}$ total battery capacity $(\mathrm{Ah})$. Here we supposed that the battery system voltage is constant.

\section{STUDY CASE}

\section{A. Electric bus model}

The electric bus is modelled with VEHLIB using a forward approach. This approach includes a driver model, which considers the required speed and the present speed to develop appropriate throttle and brake commands through a proportional-integral (PI) controller. The throttle command is then translated into a torque provided by the motor and an energy use rate. The computed torque is passed forward through the drivetrain, in the direction of the physical power flow in the vehicle, until it results in a tractive force. The battery cell and bus specifications are shown in Table I and II respectively.

TABLE I. BATTERY CELL SPECIFICATIONS

\begin{tabular}{l|l}
\hline \hline Parameters & Value \\
\hline \hline Battery Type & $\mathrm{LFP}$ \\
Nominal Energy / capacity & $64 \mathrm{Wh} / 20 \mathrm{Ah}$ \\
Nominal Voltage & $3.2 \mathrm{~V}$ \\
$\begin{array}{l}\text { Max Charging/Discharging current } \\
(10 \text { s })\end{array}$ & $10 \mathrm{C}(200 \mathrm{~A})$ \\
\hline \hline
\end{tabular}

TABLE II. ELECTRIC BUS SPECIFICATIONS

\begin{tabular}{l|l}
\hline \hline Parameters & Value \\
\hline \hline Bus Type & Standard \\
Length & $12 \mathrm{~m}$ \\
Passenger capacity & $>90$ persons \\
Weight Empty/ Full load & $13000 \mathrm{~kg} / 19500 \mathrm{~kg}$ \\
Motor type & AC Induction Motor \\
Torque Max / Braking Torque & $3000 \mathrm{Nm} /-2000 \mathrm{Nm}$ \\
Nominal / Peak Power & $110 \mathrm{~kW} / 220 \mathrm{~kW}$ \\
Battery type & Lithium iron phosphate \\
Charge Method & Quick charge (Combo CCS2) \\
Charging Power & $30 \mathrm{~kW} / 60 \mathrm{~kW}$ \\
Battery Energy / Capacity & $311 \mathrm{kWh} / 540$ Ah \\
Battery - inverter efficiency & $90 \%-92 \%$ \\
Number of packs & 13 \\
Battery Weight & $2200 \mathrm{~kg}$ \\
\hline \hline
\end{tabular}

\section{B. Charging scenario}

The electric buses are charged only at the depot from 18:00 to 7:30. As indicated previously, the charging time-slot is 30 min. This scenario is quite the same as [6] with some modifications.

Because of the large time range during charging (more than 12 hours), we chose a 30 min slot which gives for the individual a vector length of 27 , which results in a reasonable search space.

In our considered scenario, as a first step, we run the optimisation for one electric bus. In a first approach, until we develop a bus line model, we used a real driving cycle for our bus in operation as an input for the electric bus model.

The simulation of the electric bus model for a day of operation gives a final state of charge $\mathrm{SoC}=10 \%$, a battery temperature of $\mathrm{T}=25^{\circ} \mathrm{C}$ and a battery ageing $\mathrm{A}=0 \%$. These data correspond to the input of our optimisation model. Table III summarises the

\begin{tabular}{|c|c|c|}
\hline Parameters & \multicolumn{2}{|l|}{ Value } \\
\hline Number of Buses & \multicolumn{2}{|l|}{ 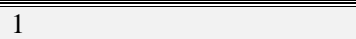 } \\
\hline Number of simulated days & \multicolumn{2}{|l|}{1} \\
\hline Charging Time & \multicolumn{2}{|c|}{ From $18: 00$ to $7: 30$} \\
\hline Charging Slot & \multicolumn{2}{|l|}{$30 \mathrm{~min}$} \\
\hline Number of charging Slots & \multicolumn{2}{|l|}{27} \\
\hline Initial State Of Charge & \multicolumn{2}{|l|}{$10 \%$} \\
\hline Initial Battery Temperature & \multicolumn{2}{|l|}{$25^{\circ} \mathrm{C}$} \\
\hline \multirow{4}{*}{$\begin{array}{l}\text { Initial Battery Ageing } \\
\text { Fixed Outside Temperature } \\
\text { Electricity costs }\end{array}$} & \multicolumn{2}{|l|}{$\begin{array}{l}0 \% \\
25^{\circ} \mathrm{C}\end{array}$} \\
\hline & $\begin{array}{l}18: 00-20: 00 \\
06: 30-07: 30\end{array}$ & $0,036 € / \mathrm{kWh}$ \\
\hline & $\begin{array}{l}20: 00-21: 30 \\
00: 30-06: 30\end{array}$ & $0,049 € / \mathrm{kWh}$ \\
\hline & $21: 30-00: 30$ & $0,043 € / \mathrm{kWh}$ \\
\hline
\end{tabular}
parameters used in our scenario.

TABLE III. SIMULATION PARAMETERS 
We chose variable electricity costs in order to see the behavior of our optimisation algorithm towards this dynamic scenario. The cost peak time is from 20:00 until 21:30, and takes up again from 00:30 to 06:30, whereas the off-peak time is from 18:00 to $20: 00$ and $6: 30$ to $7: 30$. An average electricity cost has been chosen from 21:30 to 00:30.

We will provide a simple method of setting charging schedules as baseline against which to compare NSGA-II performance. The baseline represents one typical behavior by charging the EB with an average power of $30 \mathrm{~kW}$ at 18:00, ignoring cost and battery ageing, until it is fully charged. This approach can be represented in the NSGA-II framework by a vector where each row is of the form:

$P_{1}=[30,30,30,30,30,30,30,30,30,30,30,30,0,0 \ldots ., 0]$, where the transition from charging to non-charging is determined by the initial SoC and battery capacity.

The optimisation was conducted using NSGA-II, with some modifications on genetic operators. The parameters used are shown in Table IV. Those parameters were tested and determined before in order to increase the algorithm performance while respecting constraints.

\begin{tabular}{|c|c|}
\hline Parameters & Value \\
\hline Population size & 50 \\
\hline Number of generations & 20 \\
\hline Mutation rate & 0.5 \\
\hline Crossover rate & 0.5 \\
\hline Mutation operator & Boundary mutation \\
\hline Crossover operator & Modified order crossover \\
\hline
\end{tabular}
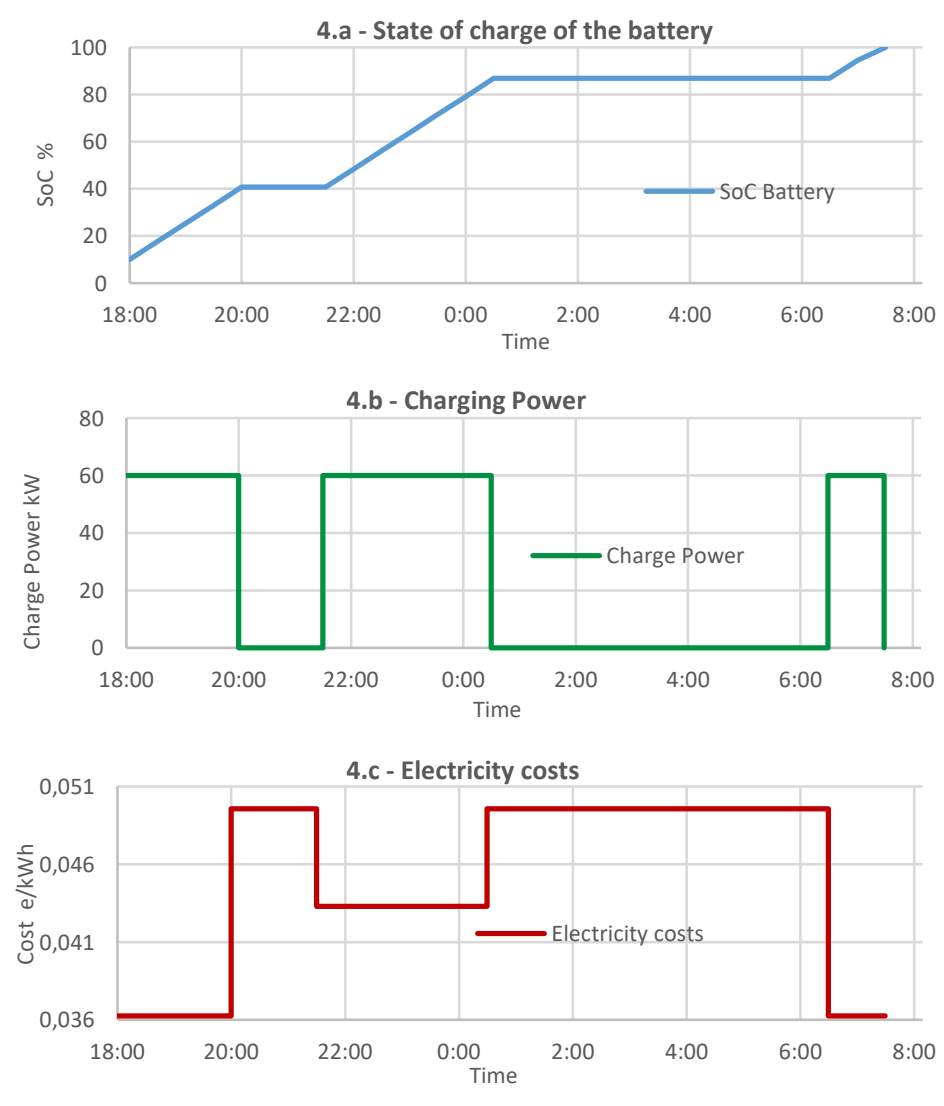

Fig. 4. Optimal charging schedules to minimise electricity costs

\section{RESULTS AND ANALYSIS}

In this paper, we are interested in minimizing the electricity costs while at the same time minimizing the battery ageing by assigning the optimal charging power with regard to technical constraints. Thus, as a first step, we focus on mono-objective optimisation by minimising the electricity costs, and then minimizing the battery ageing. To this end, the second fitness function was fixed.

The results of mono-objective optimisation for minimizing electricity costs in (Fig. 4) regardless of the battery ageing show that the optimal charging power agrees perfectly with the variation of the electricity costs. We start to charge with the maximum allowed power during the off-peak times and also when the electricity cost is low from 21:30 to 00:30.

The results of mono-objective optimisation for minimizing battery ageing in (Fig. 5) regardless of the electricity costs, show that the optimal charging power tends to charge the EB as late as possible. That is totally logical regarding to the ageing fitness function defined in Eq. (6). The calendar ageing ensures that the battery is ageing more rapidly for high SoC values.

We can observe that when the SoC is low $(10<\mathrm{SoC}<20)$, the optimal solution prefer to decrease the charging power (to 30 $\mathrm{kW}$ ) between 1:00 and 2:00. This result could be explained by the fact that during low SoC values, the temperature of the battery is the major factor in the ageing variations. Fig. 5.c supports this supposition by comparing the variations of temperature and ageing of the battery for our optimal solution with another solution called Maximal charging that charges the EB as late as possible at the maximum allowed power. We can notice that between SoC $10 \%$ and $18 \%$, the charging power at $30 \mathrm{~kW}$ is capable of achieving lower battery ageing and temperature values.
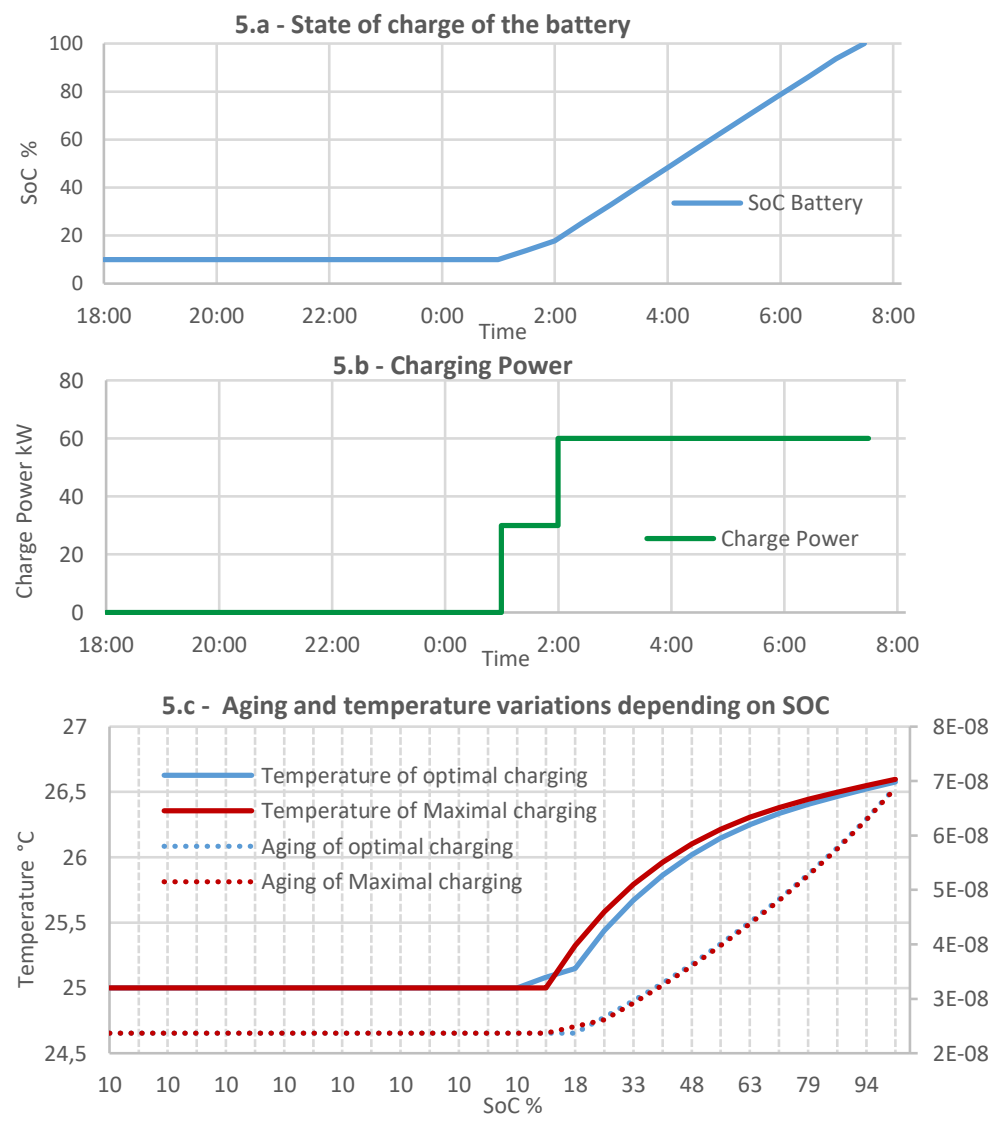

Fig. 5. Optimal charging schedules to minimise battery aging 
Thereafter, we focus on multi-objective optimisation by minimizing both the electricity costs and the battery ageing. The result of NSGA-II optimisation are summarised in (Fig. 6), showing the total evaluations performed and the Pareto front.

The Pareto front express the trade-off between these two competing objectives and proposes different solutions that have different cost and battery ageing.

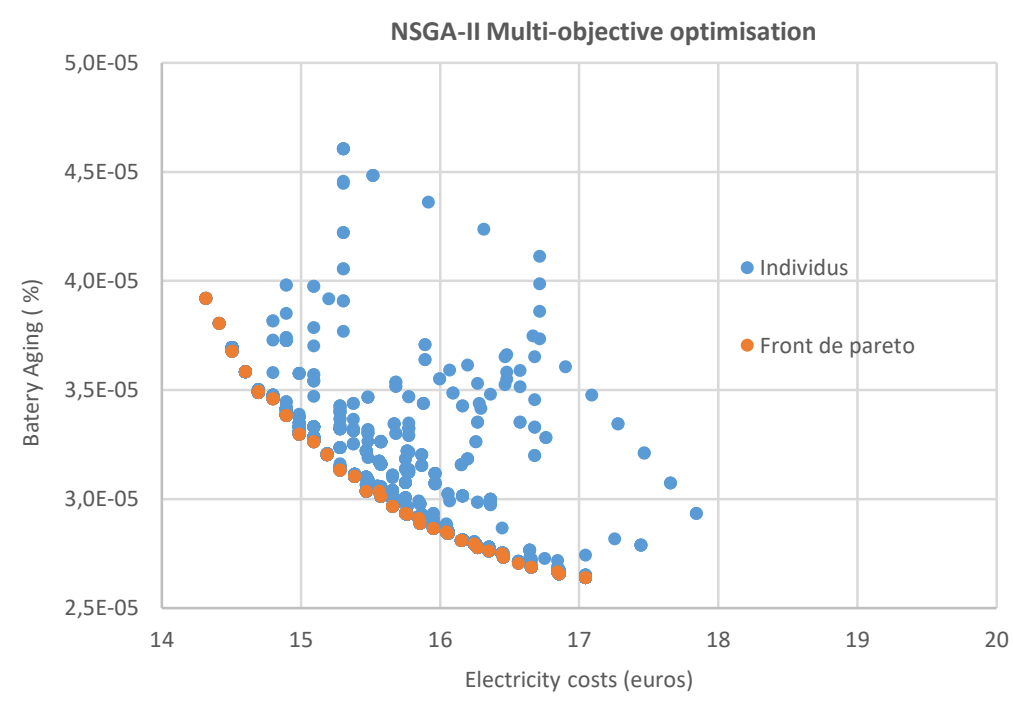

Fig. 6. Optimal charging schedules Pareto Front

During this part, we chose a random solution from the Pareto front against which to compare the baseline charging Method defined previously.
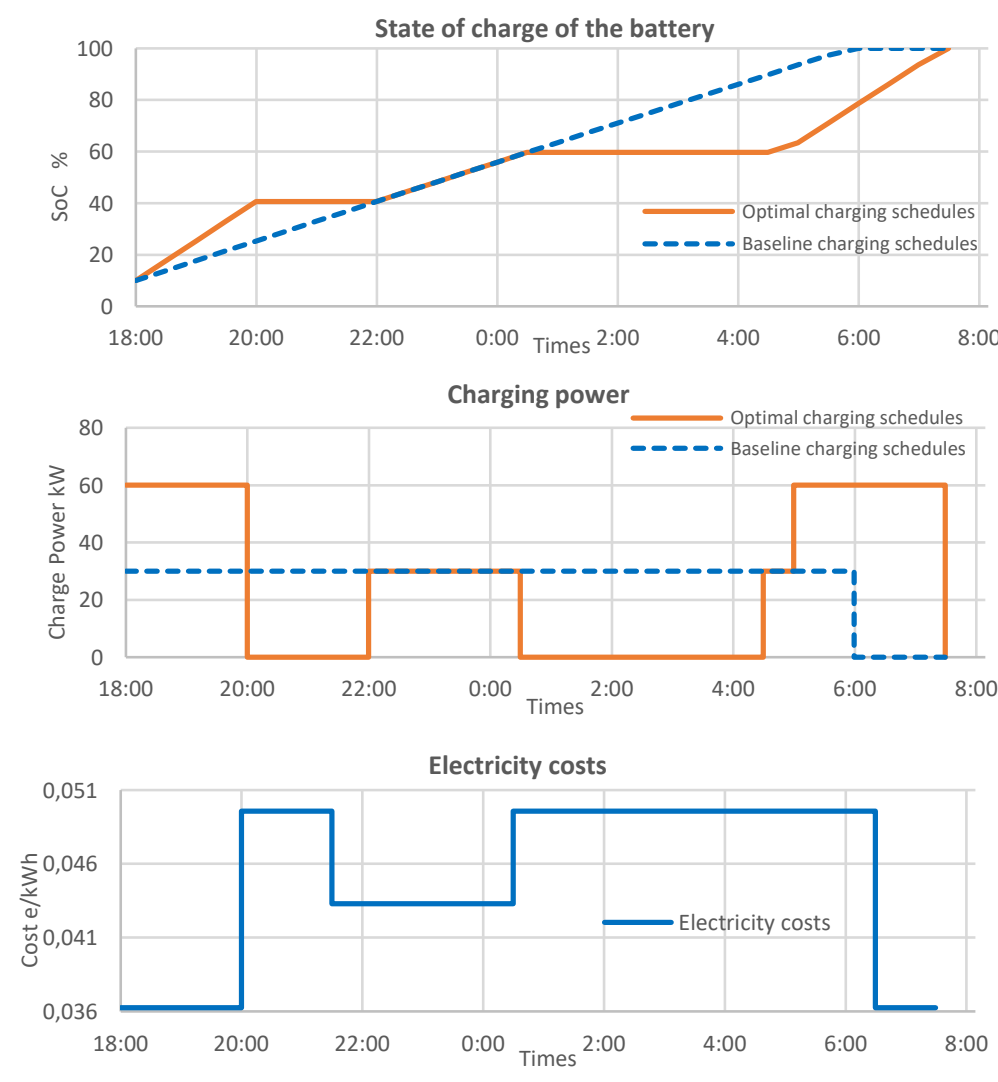

Fig. 7. Comparison optimal charging power and baseline method
The optimal charging power chosen from the Pareto front use to charge not only during the off-peak times to minimise the electricity cost but also during the latest peak times in order to find a proper balance between the two objectives. We can also notice in (Fig.7) that the optimal charging power gives sometimes an average charging power to extend battery lifetime. The results of the comparison between two types of charging present a clear decrease in cost as well as the battery ageing. The optimised price for one day's charge is about 15 euros per bus instead of 16,48 euros for the baseline method. The optimised ageing for one day's charge is $3,3 \cdot 10^{-5} \%$ per bus instead of $3,6 \cdot 10^{-5} \%$ for the baseline method.

\section{CONCLUSION}

This paper introduces an intelligent charging method for electric buses. A case study has been analysed and the implemented NSGA-II achieves good results after only 20 generations with consuming about two minutes of computing time. We have tested this approach on one electric bus with different electricity price scenario in order to better understand and validate the behavior of the algorithm for a small problem.

In future work, the purpose is to deal with a larger problem with different sizes of bus fleets over a long period of time and to see how the algorithm performs. Particular attention will be paid to alleviate the stress in power grid and reduce peak demand. It would be wise to compare variants of evolutionary algorithms in terms of performance and reducing computing time. An appropriate changes will be made in sub-models, in particular the battery model so that our approach would take account of any type of battery.

\section{REFERENCES}

[1] Eurostat. European Comission "Transport energy consumption an emissions”,URL:http://epp.eurostat.ec.europa.eu/statistics_explained/index.php/Transpo rt_energy_consumption_and_emissions[accessed April, 19th, 2017]

[2] European Commission. Climate Action Policies. Roadmap for moving to a low-carbon economy URL:https://ec.europa.eu/clima/ policies/strategies en[accessed April, 19th, 2017]

[3] J. P. Lopes, F. J. Soares, P. M. Almeida, and M. M. da Silva, "Smart Charging Strategies for Electric Vehicles: Enhancing Grid Performance and Maximizing the Use of Variable Renewable Energy Resources."

[4] R. Trigui, B. Jeanneret, F. Badin, "Systemic modelling of hybrid vehicles in order to predict dynamic performance and energy consumption. Building the VEHLIB library of models", (text in French with abridged version in English), RTS Journal, November 2003.

[5] J. Hu, H. Morais, T. Sousa, and M. Lind, "Electric vehicle fleet management in smart grids: A review of services, optimization and control aspects," Renewable and Sustainable Energy Reviews, vol. 56, pp. 1207-1226, Apr. 2016

[6] Edgar Galván-López, Tom Curran, James Mc Dermott, Paula Carroll (2015) Design of an autonomous intelligent Demand-Side Management system using stochastic optimization evolutionary algorithms Neurocomputing 170, 270-285 (2015)

[7] M. Alonso, H. Amaris, J. G. Germain, and J. M. Galan, "Optimal charging scheduling of electric vehicles in smart grids by heuristic algorithms," Energies, vol. 7, no. 4, pp. 24492475, 2014.

[8] N. Damay, C. Forgez, M.-P. Bichat \& G. Friedrich. Thermal modeling of large prismatic LiFePO4/graphite battery. Coupled thermal and heat generation models for characterization and simulation. Journal of Power Sources, vol. 283, pages 37-45, 2015

[9] Redondo-Iglesias, E.; Venet, P. \& Pelissier, S. Eyring acceleration model for predicting calendar ageing of lithium-ion batteries Journal of Energy Storage , 2017, 13, 176 - 183

[10] K. Deb, Multiobjective Optimization Using Evolutionary Algorithms. Chichester, U.K.: Wiley, 2001

[11] K. Deb, A. Pratap, S. Agarwal, and T. Meyarivan, "A Fast and Elitist Multiobjective Genetic Algorithm: Nsga-II”, IEEE Transactions on Evolutionary Computations, 6(2): pp. 182-197, 2002 